\title{
Visual failure from pituitary and parasellar tumours occurring with favourable outcome in pregnant women
}

\author{
M. A. FALCONER ${ }^{1}$ AND M. A. STAFFORD-BELL ${ }^{2}$ \\ From the Neurosurgical Unit of Guy's, Maudsley, and King's College Hospitals \\ and the Department of Obstetrics and Gynaecology, Guy's Hospital, London
}

SYNOPSIS Very few cases have been reported of a successful outcome after relief by operation of severe visual failure from a pituitary or other parasellar tumour during the late stages of pregnancy. Two such cases are recorded here together with the obstetric features and follow-up studies of more than three years. Usually the deterioration of vision occurs in the latter half of the pregnancy and recovers rapidly after delivery, whether the onset of labour has occurred spontaneously or after induction. In subsequent pregnancies vision deteriorates at an earlier stage and becomes even more marked. Some cases are now occurring even in pregnancies induced by modern fertility drugs. The treatment of choice whenever vision is seriously threatened at any stage of pregnancy is a surgical attack on the pituitary, followed by suitable replacement therapy to ensure that the pregnancy continues.

\section{CASE 1}

A 25 year old woman was admitted to the Neurosurgical Unit in March 1971 at 21 weeks' gestation with a history of rapidly deteriorating vision of two months' duration and of headache sometimes associated with vomiting. Her visual acuity four weeks before admission had been right eye $6 / 18$ and left eye 6/12 with normal fundi. Straight radiographs of the skull had been reported as normal. Within two weeks the vision of the right eye had deteriorated to hand movements only (Dr C. Constantinides). She was placed on betamethasone $4 \mathrm{mg}$ four times daily and this eased her headaches. Five years earlier she had given birth to a daughter followed by a period of lactation. There had been no visual disturbances during that pregnancy. Her menses then remained normal until the present pregnancy.

Examination on admission showed a well nourished $(72 \mathrm{~kg})$ woman from the Middle East with the uterine fundus compatible with the period of gestation. Her blood pressure was $110 / 70 \mathrm{mmHg}$. The visual acuities were left eye $6 / 24, J .10$ and right eye hand movements only, with an advanced bitemporal

1 Address for reprint requests: M. A. Falconer, Neurosurgical Unit, Maudsley Hospital, De Crespigny Park, London SE5 8AZ.

2 Present address: Canberra Hospital, Canberra, Australia. hemianopia (Fig. 1). Radiographs of the sella turcica were normal (Fig. 2). A right carotid arteriogram disclosed the presence of an avascular suprasellar mass (Fig. 3). A tentative diagnosis of a meningioma of the tuberculum sellae was made.

On 30.March, about 22 weeks after the presumed time of conception and under a cortisone cover, a right frontal craniotomy was performed under general anaesthesia (nitrous oxide, oxygen, curare, and halothane: Dr P. Hewitt) and a spherical cystic tumour about $2.5 \mathrm{~cm}$ in diameter was found beneath the optic chiasm compressing it and attached below to the diaphragma sellae. After its suprasellar portion had been removed, an aperture $4 \mathrm{~mm}$ in diameter was seen in the middle of the diaphragm, but there was no sign of the pituitary stalk which presumably had been avulsed. It was felt that there was still some pituitary tissue remaining within the sella turcica. The histological report was of a chromophobe pituitary tumour (Dr I. Janota) and this was unexpected because the sella turcica seemed normal on radiological examination. Recently Clifford and Echols (1973) reported a pituitary tumour causing visual troubles with a normal sella turcica and said that they had found only one other example in the literature. The skull radiograph of the sella turcica in our patient was more normal than it was in their case. 

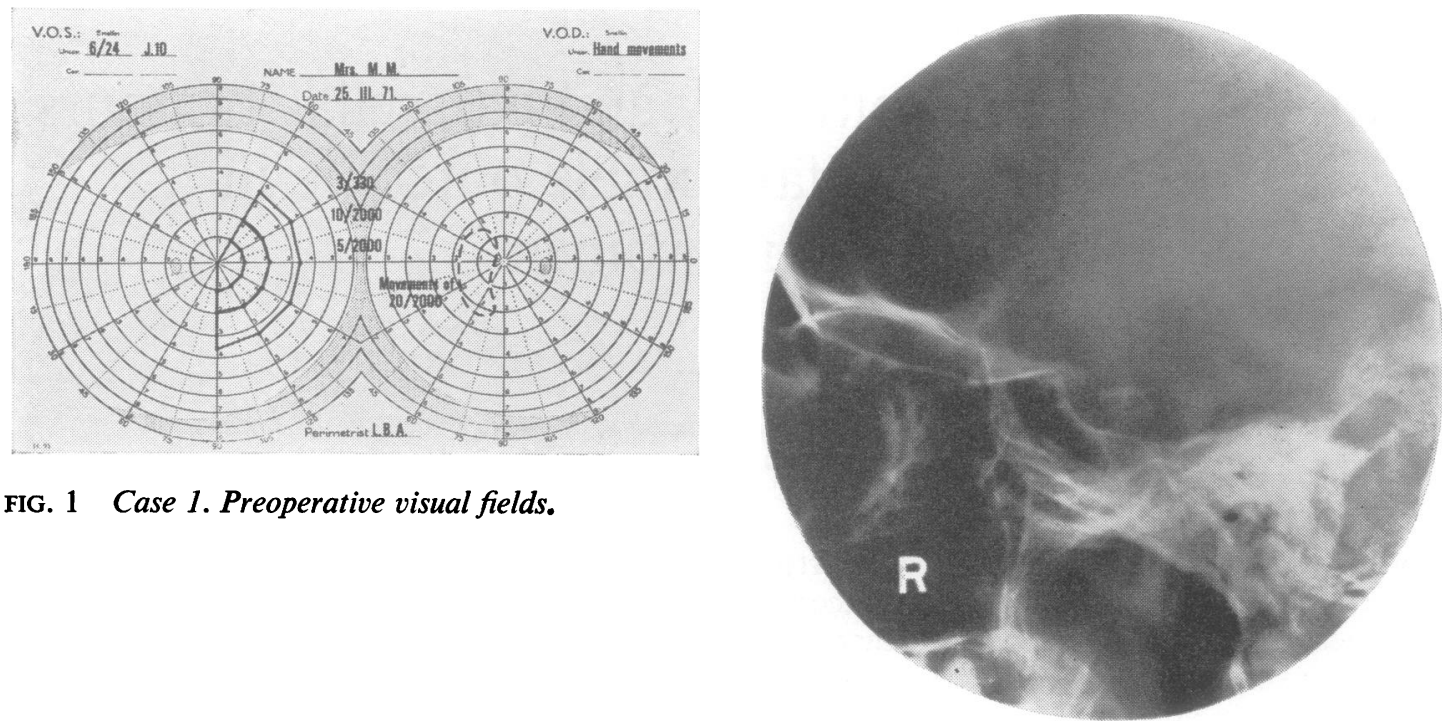

FIG. 1 Case 1. Preoperative visual fields.

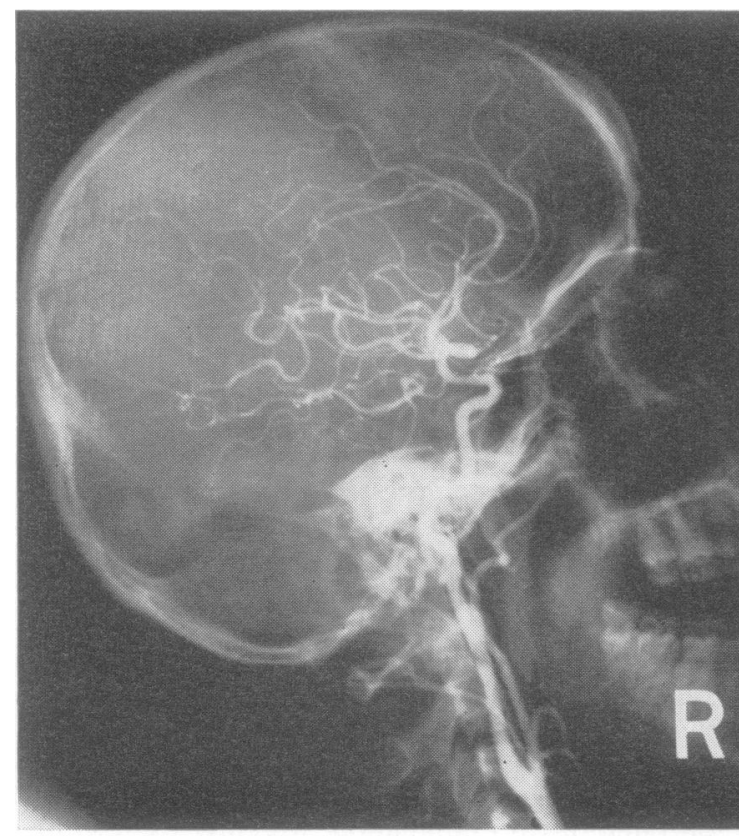

(a)
FIG. 2 Case 1. Radiograph of skull shows normal sella turcica.

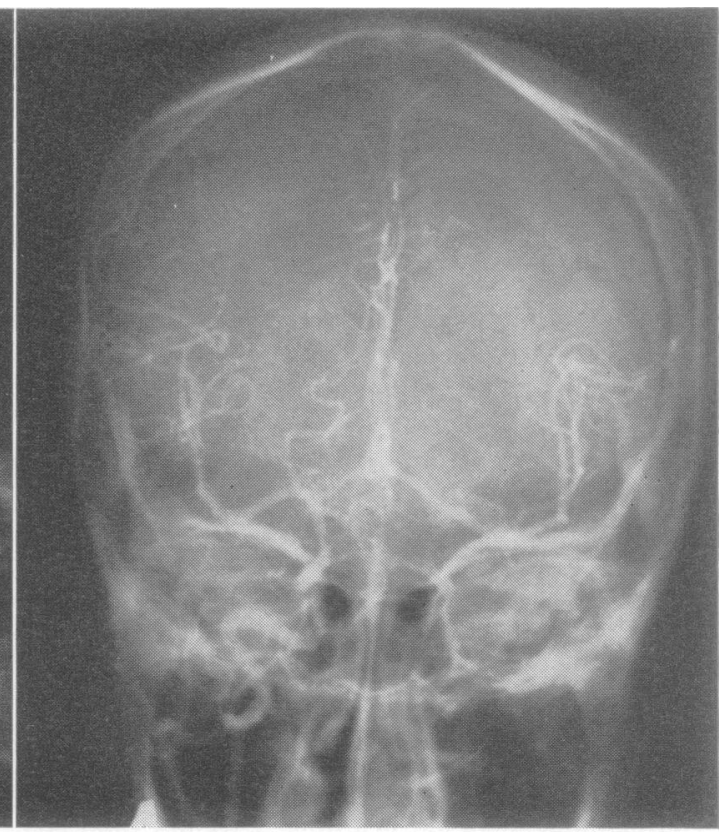

(b)

FIG. 3 Case 1. Right carotid arteriogram. Lateral view (a) and anteroposterior (b) show upward displacement of the first portions of both anterior cerebral arteries indicating a suprasellar space-occupying lesion. The left anterior and middle cerebral arteries have been filled by cross-compression of the left carotid artery in the neck. 


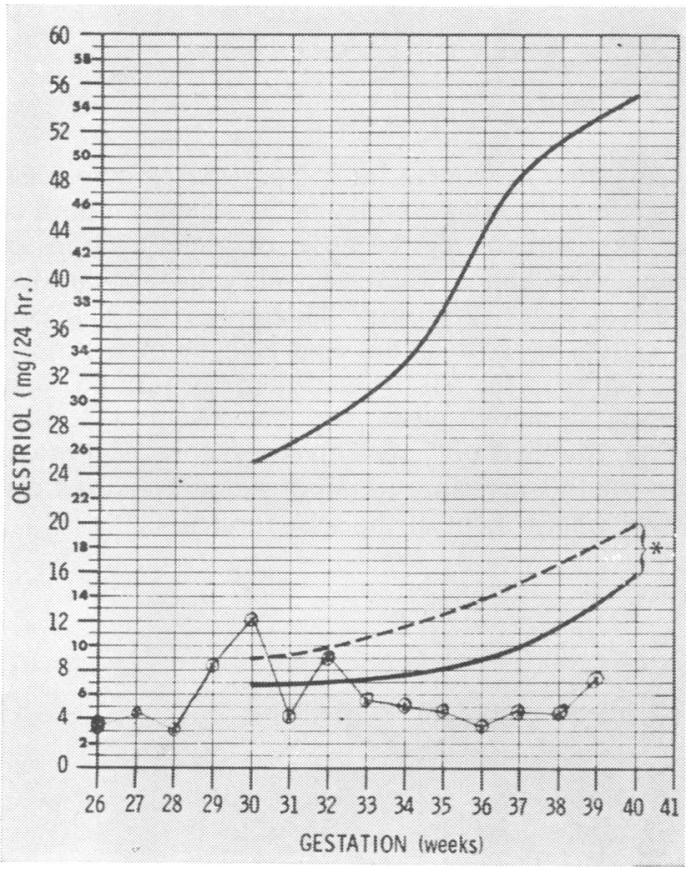

FIG. 4 Case 1. Urinary excretion of oestriol. The patient's values are encircled. The normal range lies between the continuous lines. * Borderline oestriol excretion.
During the first 24 hours after operation the patient had a urinary output of more than five litres. This diuresis was arrested by an intramuscular injection of $1.0 \mathrm{ml}$ pitressin tannate in oil every second day. By the fifth day her serum potassium concentration had fallen to $2.9 \mathrm{mmol} / \mathrm{l}$ (normal $3.5-$ $5.0 \mathrm{mmol} / \mathrm{l}$ ) and her ECG was suggestive of hypokalaemia. This was corrected with effervescent potassium drinks by mouth. Her craniotomy wound healed soundly and within a week her visual acuity had returned to $6 / 9$ and $\mathrm{J} 1$ bilaterally, with almost normal visual fields. The pre- and postoperative blood counts were normal. As a result of operation she now has bilateral anosmia.

On the ninth day she was transferred to the Obstetric Department of Guy's Hospital. During the ensuing weeks she lived outside the hospital reporting at frequent intervals. The blood levels of triiodothyronine and total thyroxine remained within normal limits for pregnancy. She remained normotensive throughout the remainder of her pregnancy. Clinical impression, satisfactory weight gain, and ultrasonic measurements of the fetal biparietal diameter all suggested satisfactory fetal growth in spite of low urinary oestriol levels (Fig. 4). However, as the other indications of fetal growth were satisfactory it was felt that these levels could be ignored. Her replacement therapy for the remainder of the pregnancy was cortisone acetate $25 \mathrm{mg}$ every eight hours, pitressin snuff by inhalation morning and night, potassium supplements, and phenotarbitone $30 \mathrm{mg}$ twice daily.

An elective lower segment caesarean section was

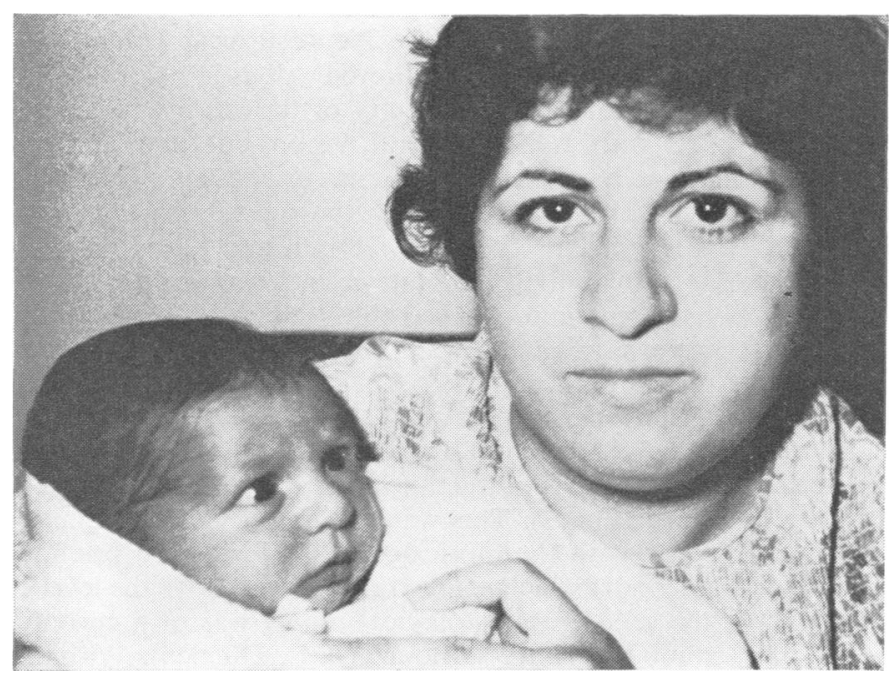

FIG. 5 Case 1. Mother and baby at three weeks. 
performed at 39 weeks' gestation and a live male infant weighing $3.2 \mathrm{~kg}$ was delivered $(\mathrm{Mr} \mathrm{T}$. L. T. Lewis). The child was slow to respond, requiring intubation (Apgar score 3, 7, 7, 8 at 1, 5, 10, and 15 minutes respectively).

Subsequently the mother and child thrived. No postoperative radiation was given to the patient. She returned to the Middle East about two months after confinement and was then on cortisone acetate $37.5 \mathrm{mg}$ and L-thyroxine $0.1 \mathrm{mg}$ by mouth daily, as well as an intramuscular injection of L-pitressin tannate in oil every second day or third day. She had not lactated, but was otherwise well (Fig. 5) except that the anosmia remained complete.

A year later she returned to Great Britain. Her weight was then $70 \mathrm{~kg}$. Recently the cortisone acetate had been replaced by prednisolone $5 \mathrm{mg}$ daily. This was changed back to cortisone. Her blood pressure was a little low at $90 / 50 \mathrm{mmHg}$. Her tendon jerks were absent. Her serum electrolytes were normal, as was her blood count and ESR. Her body hair and breasts were normal, her vagina was moist and regular sexual intercourse was taking place. She had had amenorrhoea since delivery and on three occasions her luteinizing hormone ( $\mathrm{LH})$ levels were $20.2,30.6$, and $21.8 \mathrm{IU} / 12 \mathrm{hr}$ (within normal levels), while her follicular stimulating hormone (FSH) levels were $1.7,2.3$, and $2.0 \mathrm{IU} / 24 \mathrm{hr}$ (very low) and her urinary excretion of oestrone levels were 2.1, 2.3, and $2.0 \mu \mathrm{g} / 24 \mathrm{hr}$ on three successive days (very low).

Three and a half years after her confinement she again reported back to the Neurosurgical Unit. She appeared well except for persistent diabetes insipidus for which she required an intramuscular injection of pitressin tannate in oil every fourth or fifth day. She was also taking cortisone acetate $25 \mathrm{mg}$ and Lthyroxine $0.1 \mathrm{mg}$ daily. Her weight had fallen to $64 \mathrm{~kg}$ from $72 \mathrm{~kg}$ because of dieting. Her visual acuity and visual fields remained normal as did her optic discs. The blood pressure was $110 / 65 \mathrm{mmHg}$. She still had a complete anosmia, but retained the basic tastes of sweet and sour, bitter, and acid. Radiographs of the skull still showed a normal sella turcica. Her tendon jerks had returned. She also had complete amenorrhoea. The cervical cytology was class II with no malignant cells. Her urinary excretion of oestrones was 1.8 and $2.9 \mu \mathrm{g} / 24 \mathrm{hr}$ on consecutive days. Her FSH excretion was $1.2 \mathrm{IU} / 24 \mathrm{hr}$ (low) and LH excretion was $21 \mathrm{IU} / 24 \mathrm{hr}$ (normal). Other investigations included a normal blood count with normal serum electrolyte levels, and a serum cholesterol of $7.7 \mathrm{mmol} / \mathrm{l}$ (normal 3.9 to $6.5 \mathrm{mmol} / \mathrm{l}$ ). The protein bound iodine was $569.4 \mathrm{nmol} / 1(7.2 \mu \mathrm{g} /$ dl) (normal 3.3-7.8 $\mu \mathrm{g} / \mathrm{dl}$ ). The ECG was normal. Regular sexual intercourse was still occurring without difficulty.
Her $3 \frac{1}{2}$ year old son was reported as completely normal.

\section{CASE 2}

A 23 year old woman, also from the Middle East, was referred to this country in the seventh month of her first pregnancy because of deterioration of vision. She had a mildly acromegalic appearance, and five years previously had undergone a plastic procedure to correct the enlargement of her nose. The acuity in the left eye had then been found to be slightly impaired when she underwent a test of vision. She had only recently sought medical attention for this deterioration and radiographs had disclosed enlargement of the sella turcica.

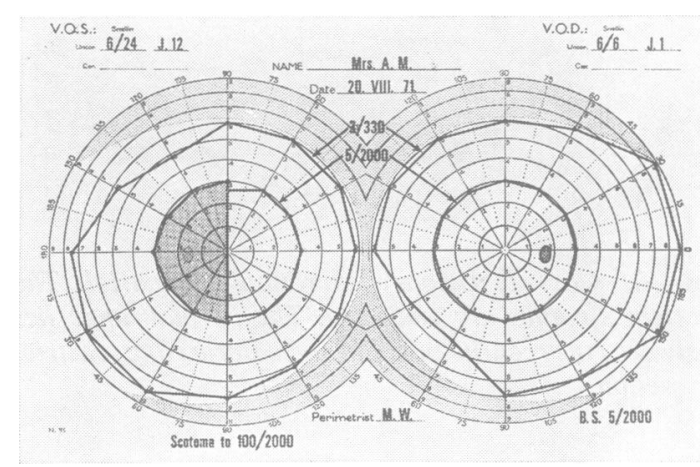

FIG. 6 Case 2. Preoperative visual fields.

On admission to the Neurosurgical Unit on 20 August 1971 she showed slightly acromegalic features. The visual acuity of the left eye was $6 / 24$, J12 with full peripheral vision but with a large dense hemicentral scotoma in the temporal half, while the visual acuity in the right eye was normal (Fig. 6). Pulse rate was $78 / \mathrm{min}$ and blood pressure $115 / 70 \mathrm{mmHg}$. Blood count was normal. The hydroxy- and ketosteroid excretions in the urine were normal as was her plasma protein bound iodine $(457 \mathrm{nmol} / \mathrm{l} ; 5.8 \mu \mathrm{g} / \mathrm{dl})$. Pneumoencephalography performed on 20 August showed a suprasellar extension of a pituitary tumour displacing the anterior part of the third ventricle upward and backward (Fig. 7). This was followed by a right craniotomy with the intracapsular removal of a pituitary adenoma which reached up $1.0 \mathrm{~cm}$ above the level of the sella. The histological report was of a chromophobe pituitary tumour (Dr L. Duchen). Within a 


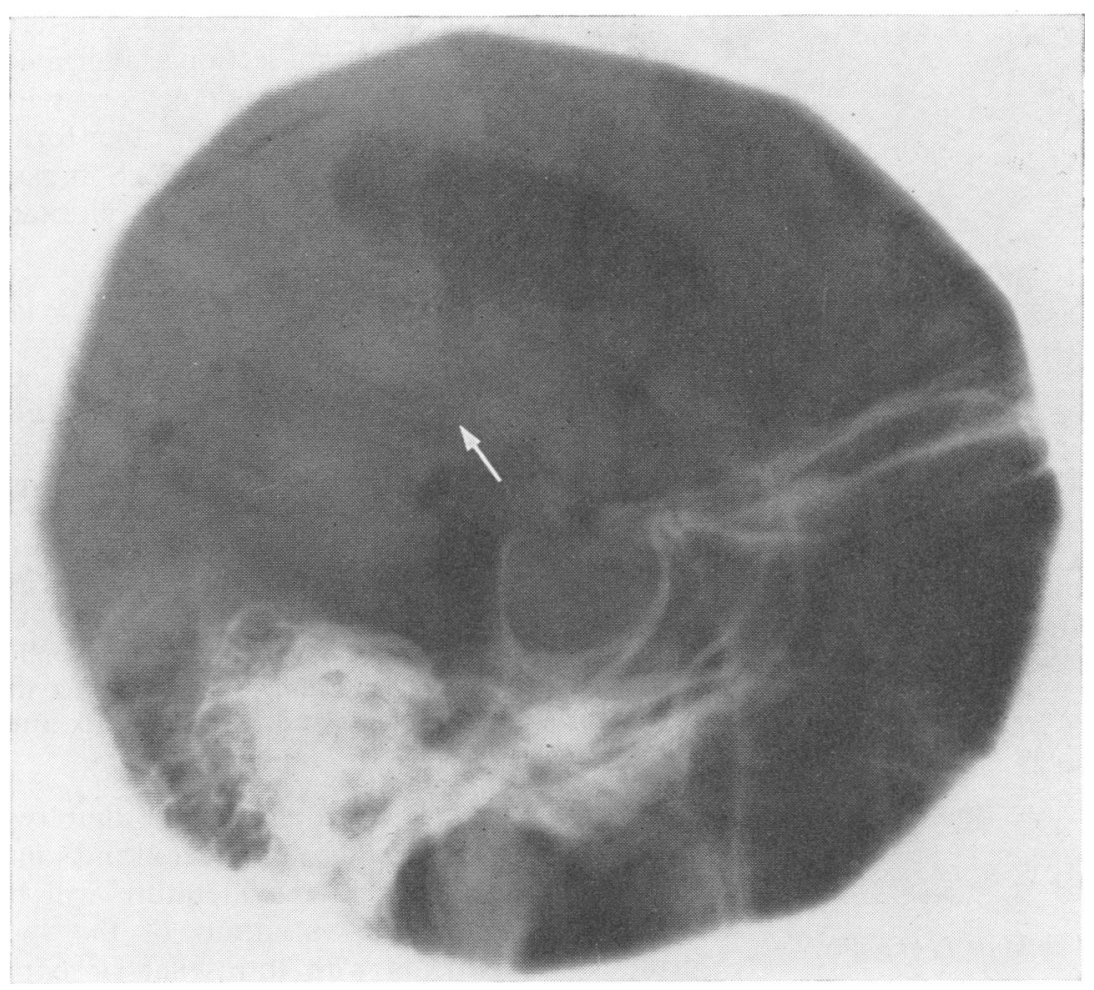

FIG. 7 Case 2. Coned lateral view of pneumoencephalogram shows a slightly dilated sella turcica with filling of the ventricular system and basal cisterns. The anterior part of the third ventricle (arrow) is displaced upwards and backwards.

week her visual acuity in the left eye was $6 / 18, \mathrm{~J} 6$ and the visual field had also improved. She then promptly returned to the Middle East. There the pregnancy continued satisfactorily until 34 weeks' gestation when she was admitted to hospital with pre-eclamptic toxaemia. Labour was induced at 36 weeks by artificial rupture of the membranes and an intravenous drip of synthetic oxytocin (Syntocinon) resulting in the normal delivery of a live male infant weighing $2.2 \mathrm{~kg}$. Lactation was not established but otherwise mother and child progressed well (Fig. 8). Smell sensibility was retained. After her confinement she had amenorrhoea, except for some irregular bleeding on three occasions in the first year. Shortly after the birth she was given radiation therapy to the pituitary, receiving a tumour dose of 4000 rads in an overall time of 37 days (Dr D. H. Mortazavi). Her visual fields still showed a slight defect in the left upper nasal quadrant. The right field remained normal.

Three years after her operation while on a visit to Great Britain it was found that she had taken no replacement therapy since the course of radiation therapy, but she appeared healthy in almost every way. Although her facial features were still acromegalic, her heel pads now measured $18 \mathrm{~mm}$ whereas before operation they were $25 \mathrm{~mm}$ (upper limit of normal is $23 \mathrm{~mm}$ ). The blood pressure was $110 / 70 \mathrm{mmHg}$. Vision was normal in the right eye at $6 / 9$, J1 uncorrected with a normal field of vision and was slightly impaired in the left eye with an uncorrected visual acuity of $6 / 12, \mathrm{~J} 4$ and a full visual field but with an incomplete central scotoma in the upper temporal quadrant to $2 / 2000$ but not to $5 / 2000$. Her energy seemed normal and there was no thirst or polyuria. Her plasma protein bound iodine was not measurable because of iodine contamination. The blood thyroxine (T4) level was 56.6 $\mathrm{nmol} / \mathrm{l}$ (low normal). The early morning and midnight plasma cortisol levels were normal. She even reported occasional menstrual bleeding at intervals of two to three months, but there was no certain evidence of ovulation (Dr H. Amini). Pelvic examination disclosed normal sized healthy pelvic organs. The urinary excretion of FSH was $6 \mathrm{IU} / 24 \mathrm{hr}$ (low) and LH $32 \mathrm{IU} / 24 \mathrm{hr}$ (normal). A cervical smear showed more oestrogenic effect than in the first 


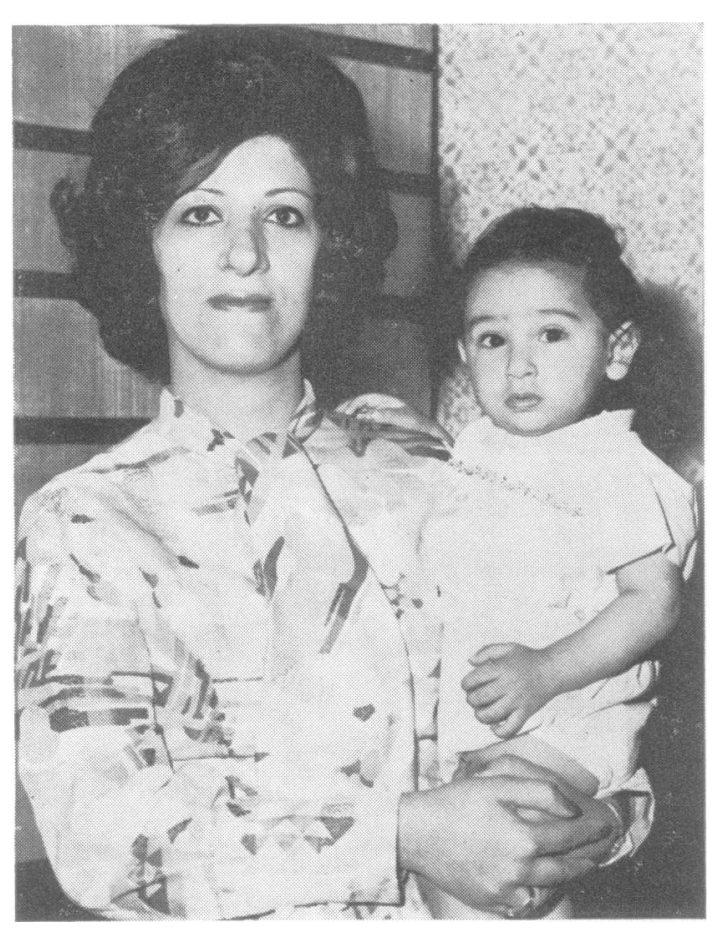

FIG. 8 Case 2. Mother and child at 11 months.

patient, without any malignant cells. An endometrial biopsy showed scanty endometrium with slight proliferative change. She and her husband were still practising contraception.

Her 3 year old son was completely normal (Dr S. Davidson).

\section{DISCUSSION}

In 1947 Sir Steward Duke-Elder wrote:

'The evidence is strong that in certain cases during pregnancy adenomatous changes may be stimulated or accelerated in the pituitary, that these may eventually involve complete bitemporal hemianopia and may progress in subsequent pregnancies so that eventual operative removal of the neoplasm is necessary. In the present state of our knowledge the relationship has now been completely established and such cases should be watched with care'.

It is our intention to show from our experience that nowadays, in cases with serious impairment of vision from optic nerve or chiasmal compression, the neurosurgeon is justified in operating upon the patient at any stage of the pregnancy to save vision, and that his obstetrical colleague should be able to carry the patient to full-term normal delivery or caesarian section as indicated.

The literature relating to pregnancy occurring in women with pituitary tumours or other forms of dysfunction is steadily increasing. Sommers (1958) reviewing the functions of the pituitary gland during pregnancy stated:

'It is generally appreciated that for a certain period of pregnancy in animals normal pituitary function is essential, since hypophysectomy early in pregnancy results in foetal death. The effects of hypophysectomy vary considerably with the species and with the stage of gestation. The critical period for women is not known. It appears to be before the 12th week of pregnancy, based on one case of pituitary necrosis in which the foetus remained alive. The corpus luteum in women is evidently non-essential after the 10th week of pregnancy. Chorionic gonadotrophin secretion in urine is found almost at once after the human blastocyst implants and rises to a peak after 8 to 10 weeks'.

From the literature it would appear that two groups of patients should be considered and some of these case reports in the literature will be reviewed to show the variations of the syndromes: (1) patients with intrasellar or parasellar tumours who become pregnant and then develop failing vision; (2) patients who have had amenorrhoea or anovulatory menstrual cycles and then become pregnant, either spontaneously? or as a result of drug therapy, before the failure of vision appears. This second type is less common but in future years may become so with increasing use of ovulation-inducing agents.

PATIENTS WITH PARASELlaR TUMOURS WHO BECOME PREGNANT AND THEN DEVELOP FAILING VISION Several authors have now reported cases of failure of vision appearing during pregnancy with interesting variants of the clinical syndromes provided by pregnancy, pituitary insufficiency, and failing vision.

Enoksson et al. (1961) reported a case of their own and summarized the literature.

Their patient, a woman born in 1930, had had from the age of 10 years attacks characterized by paraesthesias of the right face, a strange taste in her mouth, and a feeling of anxiety. At 15 years her visual acuity was 1.0 in each eye with normal visual fields, while skull radiographs showed a normal sella turcica. At the age of 24 years she came under 
observation at the 38th week of gestation with failing vision for the past two months. Her vision then was right eye 0.4 and left eye 0.2 , while her visual fields showed an incomplete bitemporal hemianopia. Radiographs of the skull now showed thinning of the posterior clinoid processes. Induction of labour by rupture of the membranes was, therefore, undertaken and next day she spontaneously bore a $3.2 \mathrm{~kg}$ healthy child. Two days later a pneumoencephalogram showed slight elevation of the chiasmal cistern but the third ventricle appeared normal. By the third day her visual acuity had improved to 0.7 in the right eye and 0.2 in the left eye. Two weeks later her vision and visual fields were once more normal.

Eighteen months later she was investigated because of amenorrhoea. Her vision then was normal and she had no signs of hypopituitarism apart from a basal metabolic rate of $-12 \%$ to $-16 \%$. Her blood cholesterol and ${ }^{131}$ I uptake were normal. The outcome as regards amenorrhoea is not stated, but in spite of advice that she should have her vision tested every six months she did not report for followup until she was aged 27, when she reappeared, pregnant for the second time at the twelfth week of gestation. A pneumoencephalogram repeated at the seventeenth week showed a suprasellar extension $10 \mathrm{~mm}$ high with a deformation of the anterior part of the third ventricle. However, she could read 1.0 in each eye, although bitemporal defects in her visual fields had appeared. As she wanted another child, periodic checking of her vision was arranged. By the 37th week her vision had fallen to right eye 0.3 and left 0.1 with a complete loss of the temporal field of the left eye as well as some reduction of its nasal half. The right visual field had a large temporal defect. The membranes were ruptured and the next day she gave birth to a healthy $2.5 \mathrm{~kg}$ child. Her vision began to improve spontaneously by the second day and by the twelfth day had recovered to 0.5 (right) and 0.2 (left) with expanding visual field. By the twentieth day she could see 1.0 with either eye and had only insignificant field defects.

Six months later it was evident that she had been having epileptic seizures all along and that they had become more severe during the last six years. However, during her pregnancies their frequency had diminished. Further radiology showed an enlarged sella turcica with a deformation of the anterior part of the third ventricle of much the same degree as in the seventeenth week of the second pregnancy. At operation the tumour proved to be a cystic chromophobe adenoma at least $2.5 \mathrm{~cm}$ behind the tuberculum. On discharge her vision was 1.0 with full visual fields on the right and 0.9 with an almost full field on the left.
Recently, Professor Nils Lundberg who had performed the operation in 1960 said that she lactated after both deliveries, but that the quantities of milk were not always sufficient (personal communication). After the pituitary operation she had amenorrhoea, and a temperature test in 1963 indicated no ovulations. Her libido was poor, she put on weight, and had low values for her basic metabolic rates and plasma protein-bound iodine levels. She was not given replacement therapy. Her seizures became mild and infrequent but she still takes phenytoin. Her general condition remains good and her vision remains normal. She runs her home and has a parttime job in a bank.

Enoksson and his colleagues (1961) also reviewed from the literature six cases of pregnant women all of whom at some stage in the latter half of pregnancy had developed visual impairment with visual field changes, usually with recovery or improvement of vision after delivery or abortion. Of the six cases, two were chromophobe adenomas, three were parasellar meningiomas, and one was a craniopharyngioma. In considering therapy for pregnant women with a sellar or parasellar tumour, they pointed out that it was usually in the latter half of pregnancy that visual failure appeared. They discussed four different therapies: (1) therapeutic abortion in the early stages, for which they found little support; (2) expectant treatment with premature induction of labour as soon as the child was viable-this is how they managed their own patient; (3) operation of the tumour during pregnancy; and (4) radiation therapy to the pituitary. They cited a patient of Rand (1957) who had bitemporal hemianopia during pregnancy with an enlarged sella turcica and who after delivery had several courses of radiation therapy, finally terminating in a pituitary operation. They also cited two cases of chromophobe tumour causing visual failure in the later stages of pregnancy and operated upon during the pregnancy with favourable outcome by Guillaumat and by Philippides respectively.

Two other cases with some similarities to our own have been reported by Kaplan (1961) and Lepoire et al. (1964). The first of these developed signs of pituitary disturbances in successive pregnancies during the first trimester and, after a pituitary operation, developed diabetes insipidus and hypothyroidism. The second case after 
similar visual disturbances and operation eventually recovered her senses.

Kaplan's case (1961) was a 41 year old woman who developed an abrupt onset of blurred vision and frontal headache one month after her last menstrual period.

Four years earlier, after seven years of barren marriage, she had conceived and had a normal infant by caesarean section. A year later she twice miscarried at the third month. With each pregnancy she had noticed headaches and blurred vision from soon after the missed menstrual period remaining unchanged until they disappeared three weeks after delivery. In her last pregnancy deterioration of vision in both eyes became gross by the fourth month with a bitemporal hemianopia. Under a cortisone cover a chromophobe pituitary adenoma was removed. Diabetes insipidus, evident on the second day after operation, required therapy with pitressin and desiccated thyroid. In the 38th week she gave birth by an elective caesarean section to a boy weighing $3.3 \mathrm{~kg}$. Scanty lactation occurred in the puerperium. Her visual fields quickly became normal but features of myxoedema appeared. Her case was subsequently followed up for three months. The author claimed that this was the first recorded case in which pituitary insufficiency had developed in the first trimester and then after a pituitary operation had resulted in a successful pregnancy.

Lepoire and his colleagues (1964) described a patient who went through four pregnancies, three with recurrence of visual failure.

Subsequently after several months an eosinophilic adenoma was removed but she did not require endocrine replacement therapy afterwards. Her first pregnancy at the age of 25 years had been normal, but in three succeeding pregnancies she developed an incomplete bitemporal hemianopia which in the second pregnancy appeared in the seventh month, disappearing rapidly after delivery, and in the third it appeared during the sixth month and disappeared one month after delivery. In the fourth pregnancy her field defect appeared during the fourth month but this time did not disappear after delivery. She developed an abundant and persistent lactation which did not respond to treatment and because of this as well as the hemianopia and amenorrhoea she was admitted to hospital. She had no sign of acromegaly but had signs of hypopituitarism and galactorrhoea. A gynaecological examination showed an atrophic uterus. At operation an eosinophilic adenoma was removed. When reviewed one year after operation she was in good health without any substitution therapy. Her galactorrhoea had per- sisted for five months after operation, followed shortly afterwards by the return of her menstrual periods. Her vision was reported as good.

PARASELLAR TUMOURS IN PREGNANCY Other parasellar tumours besides pituitary tumours can also produce the clinical picture of repeated failure of vision in the later stages of pregnancy. Hagedoorn (1937), for instance, reported the case of a woman, mother of nine children, who until then had no trouble with her vision.

In the fifth month of her tenth pregnancy she developed a central scotoma in the right eye. Vision in the right eye was 0.5 and in the left 1.0. By the seventh month she had a complete bitemporal hemianopia and her visual acuity was only $2 / 60$ in the right eye with a pale optic disc. Two months later her visual acuity was right eye $1 / 60$ and left $1 / 4$. A month later at term she bore a healthy child. After delivery her vision improved rapidly and after one month was right eye $1 / 4$ and left $1 / 2$. Seven months after delivery her vision in each eye was 0.5 and 1.0 , while the field of vision on the right still showed an almost complete temporal hemianopia with only a
slight temporal constriction on the left. When seen again a further two months later she was pregnant for the eleventh time and was in the fourth month of gestation. During this pregnancy her visual fields steadily deteriorated. By the sixth month the bitemporal hemianopia was complete and her visual acuity was right eye $1 / 60$ and left $1 / 3$. Termination of 0 pregnancy was carried out when the patient could hardly distinguish between daylight and darkness. The child $(1.9 \mathrm{~kg})$ died soon after birth. After delivery, however, vision slowly improved and 10 months after delivery the visual acuity had returned to $2 / 60$ in the right eye and 9/10 in the left eye. She still had a complete bitemporal hemianopia with also some reduction of the nasal half of the right field. Radiographs of the sella turcica throughout had evidently shown little abnormality, but exploration of the chiasmal region revealed an encapsulated suprasellar meningioma. She died of haemorrhage a few hours after operation and at postmortem examination the right optic nerve was found embedded in the tumour.

PATIENTS WHO HAVE BECOME PREGNANT AFTER INDUCED OVULATION FOLLOWING A LONG PERIOD OF AMENORRHOEA AND HAVE THEN DEVELOPED SERIOUS FAILURE OF VISION Although we have had no personal experience, it is clear from the European literature that many female patients will develop amenorrhoea or anovulatory bleeding after a pituitary operation and with drug 
therapy can be made to ovulate and encouraged to conceive and have normal children. Occasionally a patient with a treated pituitary tumour can do this spontaneously. It is therefore not surprising that the occurrence of severe visual failure has sometimes occurred in such pregnancies.

In 1964, for instance, Gemzell and Kjessler from Uppsala reported that a 35 year old woman, after the operative removal of a pituitary tumour followed by 6000 rads of radiation therapy, had developed amenorrhoea with diabetes insipidus which was treated by cortisone and thyroid therapy.

This therapy was stopped after two years and ovulation was induced by daily intramuscular injections of human pituitary gonadotrophin (HPG) for 10 days, followed by injections each day for the next three days of 3000 IU of human chorionic gonadotrophin (HCG) plus 100-120 units of luteotrophic hormone (LH). As expected, ovulation occurred and she promptly conceived. At full term she was delivered of a healthy boy by caesarean section because of a transverse presentation.

By 1973 Gemzell was able to report that at Uppsala during a 10 year period they had treated for infertility five women, aged between 26 and 35 years, who had all previously undergone operations for the removal of a pituitary tumour with consequent amenorrhoea or anovulatory bleeding. All five infertile women were treated by injections of HPG, post-menopausal gonadotrophin (HMG), and HCG. Ovulation took place after each treatment. Four of the women conceived and of these, three gave birth to twins and one to a single infant. One of the women went into labour spontaneously, while three were delivered by caesarean section close to term. Only one woman did not conceive. Thus, from this group of five, all previously operated for a pituitary tumour, four gave birth to seven infants. One woman even breast fed her baby. Gemzell and his colleagues thought that all this had been possible because a small fragment of healthy pituitary tissue must have been left behind in the sellar cavity after removal of the pituitary tumour.

Others have reported successful pregnancy after the use of fertility drugs in women with amenorrhoea after the removal of a pituitary tumour followed sometimes by full radiotherapy to the pituitary region, including, on the Continent, Linquette et al. (1970), Corral et al. (1972), and Jorgensen et al. (1973), while Burke et al. (1972) have done so in Great Britain. Much earlier, Brimble (1937) had reported that a 27 year old acromegalic patient, from whom a pituitary tumour had been removed four years earlier followed by postoperative radiation therapy, had subsequently regained spontaneous menstruation, and had in due course become pregnant and given birth to a child. This was in the days before modern fertility drugs were known. It is therefore not surprising that in recent years there have been at least three reports where pregnancy after induced ovulation has led to the stimulation of a pituitary tumour that caused failing vision during the later stages of pregnancy, necessitating an urgent pituitary operation while the pregnancy continued.

Kaytar and Tomkin (1971) reported a 30 year old woman with a history of secondary amenorrhoea for 14 months.

Menstruation which started at 15 years was regular until the age of 19 years. After marriage at 28 years she had only two irregular menstrual bleedings and she desired a child. Radiographs of the sella turcica showed that it had a double floor but she had no visual symptoms. She was treated with clomiphene citrate, human FSH and LH (Pergonal), and HCG. Conception occurred and as the pregnancy progressed she developed frontal headache towards the end of the first month. By the eighth month she was found to have a severe bitemporal hemianopia. The sella turcica was enlarged radiologically. During the 35th week of gestation a large chromophobe pituitary tumour was removed by craniotomy. The patient made an excellent recovery on cortisone and thyroxine replacement therapy, and her visual fields returned to normal. At 38 weeks she went into spontaneous labour and had a low forceps delivery of a healthy infant $(2.4 \mathrm{~kg})$. Lactation was not established. Kaytar and Tomkin (1971) suggested that, whenever a diagnosis of hypothalamic dysfunction has been made and then treatment for infertility is requested, radiographs of the pituitary fossa should be taken before gonadotrophin stimulation of the ovaries is begun.

Emperaire et al. (1972) reported a 21 year old woman with secondary amenorrhoea for five years.

Three months earlier she had had transient trouble with vision in the left eye which deteriorated from 
$9 / 10$ to $6 / 10$ with a temporal notch in the centre of the left visual field. By the time Emperaire saw her, vision was normal and examination showed normal secondary sexual characteristics, while the sella turcica was radiologically normal. Her thyroid function was low. Peritoneoscopy showed small ovaries but no other abnormality. A diagnosis of secondary amenorrhoea was made and substitution therapy (not specified) was given to ensure regular menstrual bleeding. Two years later she still complained of infertility and after other tests clomiphene was given but without success. In January 1971 she was started on HMG (human FSH and LH). Ovulation and then pregnancy occurred and she was given progesterone to protect this. At the end of the first month she developed frontal headache and during the sixth week she suddenly developed a right third nerve palsy with bilateral diminution of the visual acuity and hemianopia affecting particularly the right eye. Radiographs of the sella turcica now showed it to be enlarged. A suprasellar extension of an intrasellar tumour was demonstrated by carotid arteriography and pneumoencephalography. During the eighth week an intracapsular removal of a chromophobe pituitary tumour was carried out. Postoperatively she developed diabetes insipidus which was controlled by chlorothiazide. She was discharged on twelfth postoperative day on dexamethasone and thyroglobulin. Her pregnancy continued but she subsequently required two temporary periods of hospitalization, one for thrush, and one for an episode of vomiting and weight loss. She started labour two days after term and was delivered by low forceps of a $3.2 \mathrm{~kg}$ boy. Post-partem haemorrhage due to uterine inertia was controlled by oxytocin. Lactation started on the third or fourth day but was suppressed. Menstruation never returned and her vision evidently was good, but details of the visual fields were not published. Dexamethasone and thyroglobulin were still required.

Burke et al. (1972) described a woman who, when aged 24 years, presented with infertility and secondary amenorrhoea of a year's duration.

She had no overt sign of pituitary disease except for some galactorrhoea on breast expression. She had low urinary gonadotrophins, normal cortisol excretion, and normal thyroid functions. Radiographs of the sella turcica showed a minimal double floor appearance but it was not enlarged. Treatment with HMG (Pergonal) resulted in a single child pregnancy. During the first eight weeks she complained of increasing headache, and radiographs of the skull now showed some undercutting of the tuberculum sellae. By the fourteenth week she complained of some blurred vision in the left eye, and during the next two weeks a bitemporal visual field defect rapidly developed. She was treated by a high dose implantation of two yttrium seeds, and pituitary biopsy revealed an active eosinophilic adenoma. Subsequently the vision evidently improved and precautionary steroid replacement (prednisone $5 \mathrm{mg}$ daily) was continued throughout the remainder of the pregnancy. The serum free thyroxine factor remained normal, but severe pre-eclamptic toxaemia supervened and the pregnancy was terminated by caesarean section at 33 weeks. Subsequently the mother and baby both made good progress. Lactation was established and all was going well when the case was reported six months after birth. No replacement therapy was given.

Yet another case of visual failure due to pituitary tumour making its effects in pregnancy after induction of ovulation has been reported by Swyer et al. (1971), a 23 year old woman with increasing oligomenorrhoea and occasional galactorrhoea.

After six courses of treatment with HMG and HCG, conception occurred. Towards the end of the seventh month she developed cloudiness of vision in the left eye and soon afterwards a defect in the outer lower quadrant of vision in that eye. Radiography of the $\stackrel{\mathbb{Q}}{\circ}$ skull showed erosion of the posterior clinoid pro- 0 cesses of the sella turcica. A suprasellar tumour was $\infty$ 迎 suspected. Vision continued to deteriorate until she was nearly blind in that eye. Consequently in the ninth month labour was induced, and a normal baby girl delivered $(2.2 \mathrm{~kg})$. On the day after delivery her eyesight began to improve and rapidly returned to normal. The occurrence of lactation was not reported. As a brain scan, carotid arteriogram, and a pneumoencephalogram performed within two weeks of delivery failed to show any definite abnormality, the authors could not believe that a pituitary tumour had caused the symptoms, and even thought of the possibility of demyelinating disease. Her optic fundi were pale, particularly on the left. However, the posterior clinoid processes remained eroded. This case, when taken in conjunction with others we have cited, almost certainly had a pituitary tumour and following the general rule in such cases, this regressed rapidly after delivery.

\section{CONCLUSIONS}

We have progressed a long way since DukeElder in 1947 wrote that, during pregnancy, adenomatous change might be stimulated or accelerated in the pituitary. We now know that sometimes in the latter half of pregnancy para- 
sellar tumours as well as pituitary tumours can expand and lead to chiasmal compression, only to regress promptly after parturition. This sequence may then return in successive pregnancies, eventually going on to complete blindness, unless surgery or other treatment to the pituitary region is undertaken.

In the past decade, new problems have been raised by gynaecologists and endocrinologists. It seems possible that a woman with primary or secondary amenorrhoea due to a pituitary tumour with consequent sterility can be made to ovulate and to conceive, and then to progress to term and give birth to a normal infant. It is, therefore, not wise to give fertility drugs to a woman with amenorrhoea unless a radiograph of the skull has first been taken to ensure that there is no abnormality of the sella turcica. If there is an abnormality, even slight, periodic radiography of the sella turcica should be made at, say, monthly intervals to ensure that the sella is not enlarging. The same precaution should be taken if visual symptoms arise.

To revert to our own patients, it is not beyond the bounds of possibility that our second patient, in whom menstruation has returned after removal of an eosinophilic adenoma and a full course of postoperative irradiation, could be made to ovulate and conceive if she wanted another child, because there is probably a fragment of normal pituitary remaining within her sella turcica. In our first patient, in whom the pituitary stalk was inadvertently severed, a further pregnancy, even with new drugs, seems unlikely.

We started this discussion by quoting the view of the leading British ophthalmologist of two decades ago saying that the evidence was strong that during pregnancy adenomatous changes could be stimulated or accelerated in the pituitary. Let us finish by quoting his present day American counterparts in neuro-ophthalmology, Walsh and Hoyt (1969). Although they concede that adenomas may arise during pregnancy and quote Finlay, an early writer on the subject, as well as Lepoire (1961), they write

'that a large percentage of pregnant women develop defects in their visual fields chiefly during the later stages of pregnancy, and that these field defects rapidly disappear after pregnancy. Generalised contractions and bitemporal constriction have been described in many papers in such convincing fashion that for a time many clinicians thought that the altered fields were normal for gravid women. Others elsewhere were unable to find the field defects described by Finlay and attributed most of the field defects as functional'.

Are they right in their summing up, or have they fallen into the same trap as Swyer and his colleagues-namely, believing that, as the visual failure rapidly regresses after delivery, and neuro-radiological studies show no suprasellar extension of the gland, a pituitary tumour is unlikely?

However, all writers seem agreed that a physiological enlargement of the pituitary does occur in pregnancy, probably due to an increase of those acidophil cells associated with the secretion of prolactin (Goluboff and Ezrin, 1969). Normally, this physiological enlargement does not compress the optic nerves or chiasm. However, when a small adenoma or parasellar tumour is present, this expansion during pregnancy and rapid regression after delivery may be responsible for the episodes of visual failure observed in the pregnancies of various patients we have been considering. The evidence so far assembled seems to indicate that, dependent upon the degree of visual failure, the neurosurgeon can justifiably operate upon the pituitary at any stage of pregnancy, while the obstetrician and the endocrinologist should be able to ensure that the pregnancy proceeds to term.

We wish to thank Dr K. S. Maclean and Dr R. K. Knight who together guided us in replacement therapy, Dr R. D. Hoare for the radiological studies, Mr T. L. T. Lewis and Dr H. Amini for the obstetrical details, $\mathrm{Mr}$ John McArthur and Dr S. H. Mortazavi for the radiotherapeutic information in case 2, and Dr A. Hanied, and Dr H. Kasravi for follow-up information about our two patients.

\section{REFERENCES}

Brimble, C. G. (1937). Cited by Rand (1957).

Burke, C. W., Joplin, G. P., and Fraser, R. (1972). Pituitary tumour treated by pituitary implantation of yttrium ${ }^{20}$ during and after pregnancy (two cases). Proceedings of the Royal Society of Medicine, 65, 486-488.

Clifford, J. R., and Echols, D. H. (1973). Extrasellar expansion of a pituitary adenoma with a normal-sized sella turcica and impaired vision from an atheromatous carotid artery: case report. Journal of Neurosurgery, 39, 398-400.

Corral, J., Calderon, and Goldzieher, J. W. (1972). Induction of ovulation and term pregnancy in a hypophysectomized woman. Obstetrics and Gynecology, 39, 398-400. 
Duke-Elder, Sir W. S. (1947). Pituitary hyperplasias. In TextBook of Ophthalmology, vol. 4, pp. 3508-3509. Kimpton: London.

Emperaire, J.-L., Riemens, V., Dubecq, J.-L., Palmade, J., and Leuret, L. Ph. (1972). Hypophysectomie d'urgence à deux mois du grossesse après induction de l'ovulation. Bordeaux Médical, 5, 1901-1904.

Enoksson, P., Lundberg, N., Sjöstedt, S., and Skanse, B. (1961). Influence of pregnancy on visual fields in suprasellar tumours. Acta Psychiatrica et Neurologica Scandinavica, 36, 524-538.

Gemzell, C. (1973). Induction of ovulation in patients following removal of a pituitary adenoma. American Journal of Obstetrics and Gynecology, 117, 955-961.

Gemzell, C., and Kjessler, B. (1964). Treatment of infertility after partial hypophysectomy with human gonadotrophins. Lancet, 1, 644.

Goluboff, L. G., and Ezrin, C. (1969). Effect of pregnancy on the somatotrophic and prolactic cells of the human adenohypophysis. Journal of Clinical Endocrinology and Metabolism, 29, 1533-1538.

Hagedoorn, A. (1937). Cited by Enoksson et al. (1961).

Jorgensen, P. I., Sela, V., Buss, O., and Damkjaer, M. (1973). Detailed hormonal studies during and after pregnancy in a previously hypophysectomised patient. Acta Endocrinologica, 73, 117-132.

Kaplan, N. M. (1961). Successful pregnancy following hypo- physectomy during the twelfth week of gestation. Journal of Clinical Endocrinology and Metabolism, 21, 1139-1145.

Kaytar, T., and Tomkin, G. H. (1971). Emergency hypophysectomy in pregnancy after induction of ovulation. British Medical Journal, 4, 88-90.

Lepoire, J., Arnould, G., Tridon, P., and Laxenaire, M. (1964). Hémianopsie, récidivante au cours des trois grossesses chez une malade porteuse d'un adénome eosinophil de l'hypophyse avec syndrome aménorrhéegalactorrhée. Revue d'Oto-Neuro-Ophtalmologie, 36, 203206.

Linquette, M., Fossati, P., Dupont-Lecompte, J., Gasnault, J.-P., and Montois, P. (1970). Adénomes hypophysaires et gravido-pierpéralite. Revue Français Endocrinologie Clinique, 11, 223-232.

Rand, C. W. (1957). Two cerebral complications of pregnancy: Brain tumor and subarachnoid hemorrhage. Clinical Neurosurgery, 3, 104-141.

Sommers, S. S. (1958). The pituitary and hypothalamus. In The Endocrinology of Reproduction, pp. 59-97. Edited by J. T. Velardo. Oxford University Press: New York.

Swyer, G. I. M., Little, V., and Harries, B. J. (1971). Visual disturbance in pregnancy after induction of ovulation. British Medical Journal, 4, 90-91.

Walsh, F. B., and Hoyt, W. F. (1969). Pregnancy and pituitary affections. In Clinical Neuro-Ophthalmology, vol. 3, pp. 2124-2125. Williams and Wilkins: Baltimore. 